\title{
O hiperfexfual
}

\section{Para que serve um recém-nascido?}

EM 1860, EM UMA DE suas apresentações na Royal Society, Michael Faraday - o pai da eletricidade induzida - foi interpelado pela Rainha da Inglaterra, que ao final de sua apresentação lhe perguntou: "Tudo isto é muito interessante, Senhor Faraday, mas para que serve?".

Consta que Faraday teria respondido: "Majestade, para que serve um recém-nascido?".

Naquele momento, ninguém poderia imaginar o que estava por vir com o advento da eletrônica, o processo de informatização da sociedade e a emergência do ciberespaço. O ciberespaço é o novo espaço de comunicação da humanidade, aquele que integra algumas das mais importantes inovações no campo da eletrônica, da cibernética, da computação, da informação e da comunicação. O ciberespaço está transformando profundamente a ordem econômica e social: fala-se em sociedade da informação, era do virtual, vida digital, homem simbiótico.

$\mathrm{O}$ que chamamos aqui de hipertextual é o campo conceitual, o campo nodal, ao mesmo tempo técnico e teórico, que nos permite reencenar a história da escrita e do livro, mas também a da cultura. Tencionamos mostrar, por um lado, que as escritas hipertextuais estão engendrando uma nova "economia da escrita". Por outro lado, o hipertexto e a realidade virtual constituem os principais pólos de aplicação do ciberespaço, que nos levam a repensar a dinâmica do processo de comunicação.

Ao editor preocupado com o futuro do livro e da autonomização do campo cultural que o livro, mais do que qualquer outra mídia, contribuiu para instaurar, mas também ao humanista, que sem dúvida foi um dos principais personagens criados pelo livro, e ao especialista da informação convém pensar a respeito das transformações em curso, pois, de outro modo, como poderemos nos Diretor da ECO/UFRJ 
Martin, um dos grandes especialistas da história do livro no Ocidente, "o livro não exerce mais o poder que teve; ele não é mais o mestre de nossos raciocínios ou de nossos sentimentos em face dos novos meios de informação de que agora dispomos". ${ }^{1}$ Trata-se de localizar e designar os efeitos desta revolução, duvidosa para alguns e aplaudida por outros, em todo caso dada como inelutável ou simplesmente possível: as novas modalidades de produção, transmissão e recepção do texto condicionadas pelo hipertexto eletrônico.

Vivemos hoje a emergência de um novo espaço de produção da informação, um espaço em rede no qual a velocidade é um dos vetores que engendram enormes complicações, um espaço que ultrapassa a nossa capacidade de imaginação e que revela sentimentos antagônicos de êxtase e de temor, sentimentos que se complementam em uma espécie de sublime tecnológico.

O conexionismo generalizado da sociedade das redes de computadores criou novas formas de espaço e tempo, um espaço e um tempo topológicos, complexos, flutuantes, indefinidos, rizomáticos. Para pensarmos a nova ordem do capital - informação, a nova cultura do digital -, somos levados a pensar a partir de novos paradigmas comunicacionais que se integram em torno do conceito de hipertexto.

\section{- hiperfexto}

Sob o nome genérico de hipertexto, podemos agrupar uma diversidade de conceitos, de métodos, de sistemas e de programas muito diferentes. O neologismo forjado por Ted Nelson em 1965 sofre, hoje, de uma grande polissemia.

O hipertexto estabelece, hoje, relações variáveis com os avanços que se fazem em diferentes campos: ciência da computação, ciência da informação, cibernética, teorias das redes, teorias e sistemas de comunicação, ciências da linguagem e da cognição, história do livro e da escrita, entre outros.
Em cada um destes campos o conceito de hipertexto muda.

$\mathrm{Na}$ verdade, o conceito de hipertexto cobre uma vasta gama de aplicações e de recursos que, tomados separadamente, não são suficientes para caracterizá-lo. Para definir um hipertexto, seria interessante integrar suas principais funções em um sistema ideal.

Idealmente, um hipertexto é:

- um método intuitivo de estruturação e acesso à base de dados multimídia;

- um esquema dinâmico de representação de conhecimentos;

- um sistema de auxílio à argumentação;

- uma ferramenta de trabalho em grupo.

Em ciência da informação, o hipertexto é, antes de mais nada, um complexo sistema de estruturação e recuperação da informação de forma multissensorial, dinâmica e interativa. Dentro desta perspectiva, o hipertexto representa o último capítulo da história da escrita e do livro, o livro interativo, audiovisual e multimídia.

O livro pode ser considerado, ele também, como uma tecnologia, uma interface de recuperação de informação. Na verdade, nesta perspectiva, o hipertexto se diferencia do livro menos pelo seu conteúdo do que pela forma como aprofunda o processo de artificialização da leitura.

Vale lembrar que a idéia de hipertexto foi enunciada por Vannevar Bush, em 1945, em seu célebre artigo "As we may think". Segundo Bush, a maior parte dos sistemas de indexação e estruturação da informação era hierárquica. Ora, a mente não funciona dessa forma, mas por associações. Bush imagina então um dispositivo denominado Memex - MEMory indEX - para automatizar a recuperação de informação através de uma rede hipertextual, como uma forma de solucionar os problemas ligados ao crescimento exponencial dos documentos científicos.

O hipertexto digital incorpora às velhas ferramentas de busca da informação 
uma série de outras: a lista, o repertório, o anuário, a classificação, a bibliografia, o catálogo, o índex. Estas ferramentas, ao longo dos séculos, mudaram de suporte e, com a emergência da informática, se automatizaram e ganharam em rapidez e precisão.

Em todo caso, duas tendências orientam o enciclopedismo desde os tempos mais remotos: uma via associativa (representada pelo índex) e uma via hierárquica (representada pelas classificações sistêmicas e as referências). Em cada uma destas vias a relação entre o conhecimento e seus objetos é diferente. A imagem genealógica da árvore de conhecimento designa uma adequação perfeita entre os objetos do conhecimento, o mundo e a ordem da representação, a enciclopédia. A imagem marítima instaura uma distância, uma arbitrariedade, entre o campo da realidade e os instrumentos que levam ao seu conhecimento. Com o hipertexto, é como se a primeira via, associativa, tivesse ganho provisoriamente a batalha: a imagem mais freqüente que designa a prática do seu leitor não é a da navegação?

Em um de seus textos, Jorge Luiz Borges cita "uma certa enciclopédia chinesa" na qual está escrito que "os animais se dividem em":
a) pertencentes ao imperador,
b) embalsamados,
c) domesticados,
d) leitões,
e) sereias,
f) fabulosos,
g) seres em liberdade,
h) incluídos na presente classificação,
i) que se agitam como loucos,
j) inumeráveis,
k) desenhados com um pincel muito fino de pêlo de camelo,
1) et cetera,
m) que acabam de quebrar a bilha,
n) que de longe parecem moscas.
No deslumbramento desta taxonomia, o que de súbito atingimos é não apenas uma arbitrariedade que transgride toda imaginação, mas a inexistência de um espaço comum pressuposto pelas classificações em geral. Trata-se de um espaço heterotópico, no qual as coisas são dispostas de tal forma que solapam a linguagem ou a sintaxe que autoriza manter juntas as palavras e as coisas. A heterotopia tem o poder de justapor em um único lugar uma multiplicidade de pequenos domínios granulosos ou fragmentários que são incompatíveis entre si.

$\mathrm{Na}$ verdade, como veremos mais adiante, a via associativa, rizomática, arruína a tripartição entre um campo de realidade, o mundo, um campo de representação, o livro, e um campo de subjetividade, o autor. O hipertexto produz uma conexão entre estas instâncias, tomadas como multiplicidades e virtualidades irredutíveis.

Em todo caso, o hipertexto pode ser pensado tanto como uma ruptura quanto como uma continuidade com o universo do livro. Tudo vai depender de saber se o acento recai sobre o sistema de estruturação e recuperação de informação ou sobre a forma processual, que no hipertexto é multissensorial, dinâmica e interativa.

\section{História do livro e da escrita}

A originalidade do nosso presente, seja a do texto eletrônico em geral, seja a do hipertexto em particular, integra e potencializa cada uma das principais revoluções da cultura escrita, até então analisadas separadamente: ${ }^{2}$

- a técnica de produção e reprodução (passagem do manuscrito ao impresso);

- o suporte e a materialidade (passagem do volumen ao codex);

- e as práticas da leitura (passagem da leitura em voz alta à leitura silenciosa e os dispositivos de indexação do livro).

Vejamos cada um destes pontos, fazendo ver as enormes contribuições do hipertexto a cada um deles.

\section{A técnica de produção e reprodução}

Dentre as várias mutações sofridas pelo livro, a mais conhecida é a técnica de 
impressão inventada por Gutenberg no século $X V$, identificada por muitos como o momento de sua invenção, a qual modificou os modos de produção e reprodução do texto, sem no entanto alterar significativamente a sua estrutura.

O computador tem participado de todas as fases da produção e reprodução do texto, hoje em dia, qualquer que seja o seu suporte final. Embora os computadores tenham sido utilizados inicialmente para fabricar produtos editoriais em sua forma tradicional, a informatização abre possibilidades inovadoras para se coletar, armazenar e difundir a informação. Os computadores ligados em redes já são as máquinas impressoras do século XXI. Se Gutenberg criou um meio de reproduzir, a partir de um texto, milhares de fac-símiles, as tecnologias eletrônicas oferecem meios de criar variações infinitas a partir de um mesmo material.

A evolução contemporânea da informática constitui uma espécie de materialização técnica dos ideais modernos de apropriação dos meios de produção pelos produtores eles mesmos. Os computadores pessoais ligados em rede colocam à disposição dos indivíduos as principais ferramentas da atividade produtiva: criação, produção e difusão de informação, aquisição e produção de conhecimento. Ao unir em um mesmo indivíduo as tarefas, até então separadas, da escrita, edição e distribuição, o texto eletrônico anula as diferenças que antigamente separavam os papéis intelectuais e as funções sociais. ${ }^{3}$ É uma verdadeira revolução, pois cada um de nós pode ser o editor, o produtor, o difusor de suas próprias mensagens, em contraste com o sistema concentrador das mídias de massa, segundo o qual uns produzem e outros recebem passivamente.

\section{O suporte e a materialidade}

Ao contrário do que é comumente veiculado, para que o livro se tornasse o primeiro meio de comunicação de massa e o principal dispositivo do pensamento científico - e, porque não dizer, o primeiro sistema de ensino a distância - foi preciso que ocorressem muitas alterações, anteriores e/ou posteriores a Gutenberg. Mas nenhuma dessas modificações se compara à transformação, nos primeiros séculos da Era Cristã (século II), do livro de rolo (volumen) em livro de cadernos e páginas (codex), mutação responsável pela forma que o livro tem hoje. A passagem do rolo ao códex foi o que tornou o livro um objeto facilmente manuseável, permitindo uma leitura não-linear, ou seja, uma localização não seqüencial dos assuntos. É o códex que torna possível a paginação, o estabelecimento do índex de correspondências, os sistemas de notas. Em suma, a invenção do códex é responsável pelo conceito que nos temos hoje do livro, sua estrutura tipográfica.

Tivemos a tábua, o rolo, o códice, que durou séculos, e agora as telas. A passagem do códex à tela é vista por muitos como o fim do livro. Ora, a tela é apenas um novo suporte para os textos, assim como o foram os códices. O que está sendo distribuído pelas redes eletrônicas são textos. Nunca o livro e a leitura estiveram tão vivos. Entretanto o livro eletrônico, hipertextual, introduz três vetores totalmente novos que devem ser levados em conta: 1) a velocidade da transmissão e recuperação dos textos aumenta enormemente; 2) o leitor pode se inserir na escritura, interagir, transformar, traduzir, imprimir, enfim, ele pode mapear o texto utilizando cartas dinâmicas que lhe permitam interrogá-lo de forma jamais vista; 3) ele pode ainda criar textos em grupo utilizando os sistemas de groupware. Para resumir, ele tem muito mais controle sobre o texto, e este controle é feito com precisão e velocidade.

\section{As práticas da leitura}

O livro é uma tecnologia que levou cerca de quinze séculos para se tornar o que é hoje. Entre os vários fatores que contribuíram para facilitar a leitura dos textos, além dos já citados, destacamos a propagação do 
movimento de normatização da escrita realizada na época de Carlos Magno (séc. XII), a transformação dos modelos que orientavam a escrita, notadamente a substituição do modelo monástico pelo modelo escolástico (séc. XII), a passagem da leitura em voz alta à leitura silenciosa (séc. XII/XIV), a normatização dos dispositivos de indexação e de recuperação do livro (séc. XVII/XVIII).

Estas duas últimas transformações foram fundamentais para a história da cultura escrita e ambas estão relacionadas à artificialização da leitura. A transformação da forma de ler começou a se desenvolver mais significativamente a partir da Alta Idade Média. Até então, para a grande maioria, mesmo para o leitor culto, a leitura significava a oralização do texto. A passagem para a leitura silenciosa, que começou nos mosteiros, foi uma grande revolução. ${ }^{4}$ O novo hábito se enraíza sobretudo a partir do século XII, com a escolástica, as universidades. Antes o leitor, de certa forma, era um analfabeto. Ou a leitura era feita por um escravo, ou, para ler e entender o texto, o leitor tinha de lê-lo em voz alta. Do século XII ao século $X V$, as universidades européias vão abrindo novamente as portas da leitura, derrubando os muros eclesiásticos.

Enquanto vigorou a escrita contínua, usada pelos gregos e romanos, era muito difícil ler rápido, porque o texto era praticamente indecifrável. A separação das palavras, que começou na Idade Média, foi uma primeira grande conquista. Depois veio toda a pontuação, devido à sua importância para a legibilidade. Somente por volta dos séculos XVI e XVII é que surge a pontuação gramatical. Antes o que havia era uma pontuação de retórica, oralidade. Com o tempo vai ocorrendo uma adequação à nova leitura silenciosa, com a criação da sintaxe e das normas gramaticais. A escritura vai se modificando no sentido de facilitar a nova forma de leitura: as palavras separadas, a pontuação, o parágrafo, as maiúsculas.

Ao lado destas modificações da escritura, surge uma série de dispositivos, que poderíamos chamar de aparelhagem de lei- tura artificial: sumário, índex, notas e tudo que nos livros, nos dicionários e enciclopédias auxilia o leitor a estruturar o texto para além de sua linearidade. Como já dissemos, ler um texto é reencontrar os gestos têxteis que lhe deram o nome. Ler consiste em selecionar, resumir, hierarquizar, esquematizar, tendo em vista a construção de uma rede de relações internas e externas ao texto - intertextualidade. Todo texto se reporta a outros textos, mas também a uma imensa reserva flutuante de signos, imagens e desejos que nos constituem e que contribuem para a construção de seu sentido.

\section{Intertextualidade}

O hipertexto vai favorecer a intertextualidade em todos os seus níveis. O estruturalismo e o pós-estruturalismo reúnem, sob o conceito genérico de intertextualidade, uma série de noções distintas - dialogismo, desconstrução, obra aberta, rizoma - que nada mais são do que um processo de abertura do texto através da qual este se dá a ler como uma rede de interconexões. A idéia geral é a de que o texto não tem um sentido que preexistiria à sua leitura. Pela intertextualidade, podemos dizer que é a leitura que constrói o texto. Na verdade, a intertextualidade constitui uma forma de pensamento em rede que se contrapõe à ideologia de uma leitura passiva, guiada pela ordem dos discursos.

Hoje, uma série de autores repensam o texto em suas múltiplas relações com a ordem do discurso (Michel Foucault, Michel De Certeau, Gilles Deleuze), a história das práticas de leitura (Alberto Manguel, Roger Chartier, Guglielmo Cavallo), a escrita enquanto tecnologia cognitiva (André Lehoi-Gourhan, Jack Goody, Elizabeth Eisenstein, Pierre Lévy, Régis Debray, Sylvie Fayet-Scribe).$^{5}$

Para cada uma destas correntes, o que se apresenta, em primeiro plano, é a forma como a leitura é condicionada (ou não) pelos regimes discursivos, pelas ordens de 
leitura, pelas tecnologias intelectuais.

A principal característica do modelo da difusão consiste em abstrair do texto sua inscrição material. Como podemos explicar esta démarche puramente intelectualista $\mathrm{e}$ lingüística do texto senão pela ideologia ocidental que sustenta que nada se interpõe entre o pensamento e o texto, entre o texto e o leitor? Tudo é transparência. O hipertexto, rompendo com a seqüencialidade do texto, rompe com o modelo que toma o texto como um objeto entre um input e um out-put, entre a escrita e a leitura.

Ora, a cultura escrita sempre viveu uma grande tensão entre a ordem das coisas e a ordem das palavras, entre o livro/ árvore e o livro/rizoma. Mas também entre a ordem dos discursos e um pensamento do sujeito fundador (segundo o qual o discurso é apenas um jogo, de escrita); entre a ordem dos discursos e uma experiência originária (para a qual o discurso é um jogo, de leitura); entre a ordem dos discursos e uma universal mediação (o discurso é apenas um jogo de troca).

O que une estes autores é a capacidade de pensar a atividade de leitura em seus desvios e derivas através da página, nas metamorfoses e anamorfoses do texto pelo olho viajante do leitor. Quer se trate de um jornal ou de Guimarães Rosa, os textos só têm a sua significação através da leitura - eles mudam com ela. Em todo caso, o texto só se torna texto na sua relação com a exterioridade do leitor - que só é exterior na medida em que o texto também o é -, por um jogo de implicações e de astúcias entre duas espécies de expectativas combinadas: a que organiza um espaço lisível (uma enunciabilidade, para a ordem do discurso; uma literalidade, para a ordem do leitor; uma subjetividade, para as tecnologias da inteligência) e a que organiza uma efetuação da obra (uma leitura).

Como De Certeau mostrou muito bem, a ideologia das Luzes queria que o livro fosse capaz de reformar a sociedade e a nação. ${ }^{6}$ Este mito da Educação inscreveu uma teoria do consumo na política cultural.
Pela lógica do desenvolvimento técnico e econômico que ela mobilizou, esta política conduziu ao sistema atual da difusão que inverteu a própria ideologia das Luzes: os meios de difusão se tornaram mais importantes do que as idéias difundidas.

A idéia de uma produção da sociedade por um sistema escrito teve como corolário a convicção de que o público é modelado pelo escrito. Supõe-se que assimilar significa necessariamente se tornar semelhante ao que se absorve, e não tornar semelhante ao que se é, fazê-lo seu, apropriar-se dele, reapropriar.

A leitura - numa sociedade em que a escrita tem um poder de modelagem dos costumes, do estado e do indivíduo - é apenas um aspecto parcial, mas fundamental do consumo, de tal forma que podemos pensar o binômio produção-consumo a partir do binômio escrita-leitura.

O funcionamento social e técnico da cultura contemporânea hierarquiza estas duas atividades: escrever é produzir um texto; ler é apenas recebê-lo de um outro, é reproduzi-lo. A relação que existe entre leitura e texto sagrado se reproduz, hoje, entre a leitura e a Igreja das mídias.

O que está em jogo não é a divisão do trabalho (por demais real, aliás) mas a assimilação da leitura a uma passividade.

Ontem, o texto era escolar, hoje ele é a sociedade mesma. Ele tem forma urbanística, industrial, comercial, televisiva ou hipertextual. A mutação que fez passar da arqueologia escolar à tecnocracia das mídias não foi responsável pela idéia da passividade do consumo, ela apenas a reforçou. O aperfeiçoamento do sistema disciplinar, a racionalização da gestão e a lógica da especialização produtivista também contribuíram para uma visão de que a eficácia da produção implica a inércia do consumo.

É a hierarquização social e não a seqüencialidade técnica do texto que aprisiona a prática da leitura, a aliena: o texto era a reprodução das relações sociais no interior da instituição cujos pressupostos fixavam o que devia ser lido. Com a inflechissement 
das instituições aparece entre o texto e seus leitores a reciprocidade que elas escondiam, como se, ao se retirar, ela deixasse ver a pluralidade indefinida das "escritas" produzidas por seus leitores. Este fenômeno, visível depois da reforma, hoje se faz através dos dispositivos sociopolíticos do Estado e dos meios de comunicação de massa.

\section{Ler é pensar em rede}

Ler é peregrinar em um espaço ou sistema imposto (análogo aos espaços urbanos, aos supermercados). Análises recentes mostram que toda leitura modifica seu objeto e que (como Borges já dizia) uma literatura difere de outra menos pelo seu texto do que pela forma como é lida.

Se então um livro é um efeito, uma construção do leitor, devemos focalizar a operação própria do leitor, que não toma o lugar do autor. O leitor lê no texto algo que difere da intenção do autor. Ele desloca o texto de sua origem, acessória ou perdida. Ele combina os fragmentos e os rearticula no espaço que organiza suas capacidades de produção em uma pluralidade indefinida de significações.

Independente das velhas e novas ortodoxias, se esconde a atividade silenciosa, transgressiva, irônica e poética dos leitores, que conservam sua parte, que é sempre a verdade dos mestres e dos dominadores, para além das verdades preestabelecidas.

Desde sempre, encontramos certas práticas de leitura que transgridem as ordens preestabelecidas. Em 1588, o engenheiro italiano Agostino Ramelli descreve uma engenhosa e bela máquina de leitura, muito útil e eficiente para aqueles que queriam ler uma grande quantidade de texto sem sair do lugar. $\mathrm{Na}$ verdade, tratava-se de uma máquina que possibilitava a realização da leitura extensiva em uma velocidade espantosa. A máquina permitia que o leitor pudesse ler uma dúzia de livros ao mesmo tempo. No fundo, esta máquina poderia ser colocada na origem dos modernos dispositivos eletrônicos que possibilitam a navegação intertextual ou hipertextual. Assim como o leitor do livro manuscrito podia reunir em um único exemplar obras de naturezas diversas - nisso que os italianos chamavam de libro-zibaldone -, o leitor da máquina de leitura, como mais tarde o leitor da idade eletrônica, pode construir à vontade conjuntos textuais originais, cuja existência só dependem dele.

Stendhal antecipava os dispositivos hipertextuais em suas práticas intelectuais. Para diminuir suas falhas de memória, ele fazia encadernar, em um mesmo volume, trechos de obras abolindo a fronteira habitual dos livros. A escrita é, aqui, mais do que apenas uma extensão externa da memória. Como na máquina de leitura, ela é um processo de produção que leva a um novo texto, que não preexistia propriamente à leitura.

Macedônio Fernandez, em seu romance Museo de la Novela de la Eterna (1934), o primeiro romance teórico de toda a literatura ocidental, descreve o leitor ideal. Para Macedônio, o leitor ideal é o leitor que salta, o leitor hipertextual:

“Espero firmemente não ter leitor seguido. Seria ele quem poderia me fazer fracassar e me despojar da celebridade que mais ou menos desajeitadamente procuro escamotear para alguns de meus personagens. E o fracasso é um luzimento que não assenta bem na minha idade.

Ao leitor que pula páginas me dirijo. Asseguro-te que leste todo o meu romance sem te dares conta, te tornaste leitor seguido à tua revelia, à medida que vou te contando tudo dispersamente e antes de iniciar o romance. Comigo, o leitor que salta é quem mais se arrisca a ler seguido.

Quis te distrair, não te corrigir, porque és o leitor sábio, pois pratica a entreleitura, a que mais forte impressão lavra, de acordo com minha teoria de que personagens e acontecimentos 
apenas insinuados, habilmente truncados, são os que mais se inscrevem na memória.

Dedico-te meu romance, Leitor que salta; me agradecerás uma nova sensação: a de ler seguido. Em revan-che, o leitor seguido terá a sensação de uma nova maneira de saltar as páginas: a de seguir o autor que salta." 7

Do livro múltiplo, acentrado e infinito, tal qual o Livro de areia de Borges, podemos dizer o que Barthes dizia, em $S / Z$, a respeito do livro ideal:

- no livro ideal abundam muitas redes que atuam sem que nenhuma delas se imponha às demais;

- o livro se torna uma galáxia de significantes e não uma estrutura de significados;

- não tem princípio, mas diversas vias de acesso, sem que nenhuma delas possa ser qualificada como principal;

- os códigos que mobiliza se estendem até onde a vista alcança, são indeter-mináveis;

- os sistemas de significado podem se impor a este texto absolutamente plural, mas o seu número é ilimitado, uma vez que está baseado em uma infinidade de linguagens.

\section{- rizoma}

A concepção barthesiana do livro ideal apresenta alguns princípios análogos ao que Deleuze e Guatarri vieram a chamar de rizoma, ${ }^{8}$ conceito que reúne algumas das principais figuras de expressão da cultura contemporânea e em particular do hipertexto e do ciberespaço: multiplicidade, heterogeneidade, acentramento, infinitude, metamorfose. Cabe lembrar que Pierre Lévy ${ }^{9}$ se serviu do rizoma para definir as metáforas da rede hipertextual.

Interessa-nos retomar alguns princípios do rizoma hipertextual como imagem das redes.
Princípio de conexão: qualquer ponto de um rizoma pode ser conectado a qualquer outro e deve sê-lo. No rizoma, as conexões se fazem por proximidade, por vizinhança. A rede hipertextual é uma galáxia de conexões acentradas, topológicas, que se opõem ao modelo da árvore, hierarquizado.

A topologia se define em matemática como "o estudo das propriedades invariantes das deformações geométricas dos objetos e das transformações contínuas aplicadas aos seres matemáticos". Transposta para o domínio das redes hipertextuais, isto nos levaria ao estudo das relações entre as diferentes partes de um texto.

Deste ponto de vista, valeria a pena explicitar algumas possibilidades de relação entre os diversos módulos ou partes de um texto.

Não-linearidade: no hipertexto eletrônico, ao contrário dos textos impressos, a ordem dos módulos do texto é arbitrária e pode ser permutada ou combinada, seja em função do percurso do leitor, seja em função de um agente cibernético, que as combina aleatoriamente. Este tipo de procedimento foi amplamente empregado pela literatura combinatória explorada pelas vanguardas artísticas literárias em todo mundo.

Multilinearidade: em um texto estático, os módulos podem mudar de ordem, mas permanecem idênticos. Em um texto dinâmico, os módulos podem mudar, ou seja, seu conteúdo pode mudar de acordo com o percurso do leitor.

Temporalidade: os módulos podem se transformar, seja em sua ordem, seja em seu conteúdo, dependendo da interação com o usuário.

Interatividade: existem pelo menos dois tipos de interatividade: a primeira depende das diversas formas de relação hipertextual, que podem ser explícitas, implícitas ou arbitrárias. Uma segunda forma de interatividade se faz em função das possibilidades que o sistema oferece ao usuário para interferir e transformar o texto: neste caso, em que o leitor se torna co-autor do texto, podemos falar em interatividade forte. 
Enquanto que a não-linearidade pode ser plenamente realizada em um texto impresso, pela leitura, a multilinearidade, a temporalidade e a interatividade plena dependem de sistemas hipertextuais dinâmicos que utilizam complexos sistemas de cálculos booleanos e probabilísticos combinados com a semântica estrutural.

Princípio de heterogeneidade: o segundo princípio revela que as cadeias semióticas não são de natureza exclusivamente lingüística, ou seja, da ordem do significante. Uma cadeia semiótica é como um tubérculo que aglomera atos muitos diversos, lingüísticos, mas também perceptivos, gestuais, cognitivos. A rede hipertextual provoca uma hibridização entre as diversas mídias utilizadas. Do ponto de vista da produção editorial, este fato representa uma reviravolta completa, pois, cada vez mais a produção editorial se volta para o campo da multimídia.

$O$ hipertexto multimodal, contendo textos, imagens e sons, é chamado, hoje, de multimídia ou hipermídia. $\mathrm{O}$ hipertexto multisensorial não é apenas mais uma mídia cujo acesso à informação se torna mais lúdico. Entre os livros e a hipermídia de hoje, a diferença fundamental reside em que a hipermídia permite a retradução desse código comum (o alfabeto e o digital) fora do espaço e do espírito e dos sentidos humanos. Não é difícil se dar conta de que os livros podem nos fazer interiorizar (e o fazem com efeito) a maior parte e mesmo toda a nossa "experiência externa da vida real" potencial. O audiovisual e os mundos virtuais dos computadores, por sua vez, coletam o material interno - nossos processos mentais mais preciosos - para levá-los para o exterior, nas telas. Os dispositivos hipertextuais constituem uma espécie de reificação e exteriorização dos processos de leitura. É claro que este processo não é novo; ele teve início com a produção audiovisual.

Durante o século XIX e o início do XX, o nível de utilização dos acervos audiovisuais é muito fraco, se comparado com a importância do audiovisual na nossa cultura hoje. Foi preciso esperar o aparecimento de outras formas de enciclopedismo e a criação de ferramentas como o hipertexto, a hipermídia e as redes de comunicação digitais para encontrarmos sistemas de recuperação de informação de documentos audiovisuais.

Como explicar a resistência à apropriação dos documentos audiovisuais no empreendimento das enciclopédias e bibliotecas do século XX? Tudo leva a crer que grande parte da dificuldade está relacionada com a natureza mesma do audiovisual. Por seu caráter analógico e por não comportar unidades determináveis que possam ser combinadas - em outras palavras, por sua linearidade e ausência de codificação de suas unidades -, o audiovisual não se deixa enquadrar facilmente por um sistema de indexação que é essencialmente combinatório e não-linear.

A singularidade dos documentos audiovisuais reside em sua temporalidade intrínseca: ao contrário do livro, em que o leitor é também o sistema de decodificação, o audiovisual demanda a mediação de um aparelho de execução. Além disto, sua seqüencialidade não pode ser apreendida sinoticamente.

O audiovisual não produziu suas próprias ferramentas de análise, de classificação, o que o tornou impróprio a todos os métodos combinatórios que presidem o enciclopedismo. Muitos daqueles que acreditavam, de boa-fé, criar bibliotecas audiovisuais, na verdade não se davam conta de que produziam apenas arquivos.

Combinado aos sistemas hipertextos, as tecnologias digitais representam para o audiovisual uma transformação essencial, epistemológica e heurística. Para tanto, o desenvolvimento de hipertextos audiovisuais supõe a implementação de sistemas digitais de reconhecimento e segmentação das unidades a serem recuperadas, sistemas de visualização da estrutura das unidades que se combinam no interior dos documentos e sistemas de indexação das unidades e dos documentos.

Disponibilizar o acesso ao audiovisual 
representa uma reviravolta pois significa colocar à disposição do grande público acervos que, embora tenham contribuído para formar a cultura contemporânea, eram acessíveis apenas a especialistas.

Princípio de multiplicidade: é o princípio da concepção deleuziana do transcendental e do virtual, pois ele é a condição de toda existência sem ser ele próprio jamais atual enquanto tal. Traduzindo em termos da idéia de um livro rizomático, diríamos que não há mais uma tripartição entre um campo de realidade, o mundo, um campo de representação, o livro, e um campo de subjetividade, o autor, mas um agenciamento põe em conexão estas instâncias em suas multiplicidades irredutíveis. A escrita rizomática se faz em nome de um fora, que não tem imagem, nem significação, nem subjetividade.

Em termos da rede hipertextual, diríamos que o hipertexto é fractal, ou seja, cada nó da rede hipertextual é apenas uma atualização possível entre outras, cada nó é potencialmente uma outra rede, ao infinito. A rede não possui unidade orgânica, ou seja, uma totalidade, nem centro, ela é acentrada. Na verdade, seguindo Barthes, na rede abundam muitas redes que atuam sem que nenhuma delas se imponha às demais, e além disto não há princípio, mas diversas vias de acesso, sem que nenhuma delas possa ser qualificada como principal.

A multiplicidade pode ser explicitada como uma multitemporalidade. Vivemos na era das redes hipertextuais, em que o tempo se contrai e se expande. O tempo, hoje, é, paradoxalmente, um tempo de máxima concentração, pontual, e de máxima expansão, multitemporal. Ora o aqui e agora e o instantâneo real, ora a multitemporalidade, ou seja, uma temporalidade complexa dos fluxos de comunicação que arruínam o aqui e agora. O conexionismo generalizado tende uma de suas faces para os pontos ou nós da rede e uma outra face para as suas múltiplas conexões.

Apreende-se o modo como as novas tecnologias de comunicação podem estar transformando a experiência do tempo e do espaço: o sentido da presença, a definição do próximo e do longínquo no espaço e no tempo, a distinção entre real e imaginário - todas estas fronteiras estão sendo postas em questão pelas novas tecnologias.

A rede fractal é proteiforme. Cada uma de suas múltiplas dimensões é fractal, ou seja, uma dimensão intermediária. A rede é algo que há entre os nós e as conexões. Pensemos em Proteu. Proteu existe em algum lugar entre o ponto e a linha, ou seja, entre cada uma de suas imagens e as conexões possíveis que existem entre elas. Proteu é água, é fogo, é pantera. Mas quem é Proteu quando não é mais fogo e não é ainda pantera? Em "A nova refutação do tempo", Borges nos dá um princípio de resposta: o tempo é a substância mesma da qual sou feito: o tempo é o rio que me carrega, mas eu sou o rio; é o tigre que me rasga, mas eu sou o tigre; é o fogo que me consome, mas eu sou o fogo..."..$^{10}$

$\mathrm{Na}$ verdade, o rizoma é o paradigma de um conhecimento hipertextual que rompe com dois dos maiores paradigmas que dominaram a ciência ocidental. A divisão cartesiana entre sujeito e objeto dominou o ocidente nos três últimos séculos. Hoje, a questão da realidade e do conhecimento se propõe em função de uma nova matriz conceitual. As teorias científicas e artísticas contemporâneas não pensam mais a realidade em grupos de diferentes objetos, separados de nós, mas em grupos de diferentes interações que incluem o observador. Quando hoje se fala em interatividade (por ser sensório-motora) na multimídia, trata-se do que chamamos de interatividade pobre, se comparada a esta que existe e que se estabelece como novo paradigma no campo do conhecimento. Como conhecer sem levar em conta a interação que se estabelece com o objeto do conhecimento? Ou melhor, como conhecer sem levar em conta as redes de interconexões infinitesimais dos fenômenos?

O conceito de rede tem gerado frutos muito importantes no campo da histó- 
ria e antropologia da ciência, com Isabelle Stengers, Bruno Latour e Michel Callon, entre outros. Pela primeira vez na história do ocidente estamos começando a abandonar o platonismo. Segundo Latour, ${ }^{11}$ quando medimos as informações em bits e bauds, quando somos assinantes de um banco de dados, quando, para agir e pensar, nos conectamos a uma rede de comunicação, é mais difícil continuar vendo o pensamento como um espírito flutuando sobre a águas. Hoje a razão se assemelha muito mais a uma rede de comunicação, uma rede de telemática, do que às idéias platônicas.

Seguindo esta perspectiva, a ciência é produzida coletivamente e sua produção está longe de ser apenas uma atualização das idéias e intuições de seus cientistas. Esta é uma imagem da ciência que herdamos de Platão, e que nos tem custado muito caro.

A modernização da sociedade, hoje, está ligada à entrada no mercado mundial e ao desenvolvimento científico e tecnológico. Para abordar estes temas existem dois modelos: ${ }^{12}$ um, chamado de modelo de difusão, no qual os atores se encontram paralisados pela falta de espaço de manobra: ou nos adaptamos às imposições ou bem desaparecemos, e outro, o modelo de rede, no qual, ao contrário, os atores dispõem de uma margem de manobra e de capacidade de iniciativa.

Tomemos como exemplo a questão da ciência. Para o primeiro modelo, a ciência remete a um mito fundador, compartilhado pelas histórias da ciência: a ciência é antes de mais nada as idéias de alguns homens bem-dotados. A idéia e a teoria são tudo. A ciência é o produto de teorias de especialistas que, com o tempo, e por milagre, se transformam em aplicações que vão beneficiar a sociedade. Que a ciência seja produzida apenas por uns poucos, em alguns poucos centros mundiais como New York ou Paris, que ela seja exterior ao mundo social e econômico, nada disso incomoda. É pegar ou largar.

A esta visão tradicional e romântica, para não dizer platônica e elitista, é preciso sobrepor uma outra, alimentada por uma possibilidade de ação estratégica. O modelo da rede se apóia sobre uma observação banal: nos laboratórios de pesquisa não se produzem teorias abstratas. Produzem-se, claro, textos, enunciados, imagens, gráficos e artigos. Mas o que se produz mais freqüentemente são procedimentos e experiências. Os pesquisadores, mesmo os mais experientes, os mais fundamentalistas, organizam provas e testes, inventam técnicas e instrumentos de medição. As teorias são apenas a pequena parte que emerge do grande iceberg. A parte mais importante são as práticas e a enorme rede sociotécnica mobilizada. Estatísticas mostram que a ciência fundamental é a combinação de 90\% de savoir-faire que mobiliza uma rede enorme e $10 \%$ de intuição e teoria.

Uma idéia, um enunciado e um artigo que escapam das mãos de seu autor só podem circular e produzir frutos se encontrarem atores competentes e equipados, mas também se conseguirem despertar o interesse e mobilizar as redes e instituições científicas. Se a ciência dependesse apenas das idéias para se fazer ela não se faria apenas em alguns centros. O que se produz e se reproduz cientificamente são as redes sociotécnicas, que envolvem infra-estruturas e competências incorporadas complexas. Ou seja, a ciência, para circular, depende de verdadeiras redes logísticas bem equipadas e instrumentalizadas.

As obras de Michel Callou e Bruno Latour estão repletas de exemplos que mostram que um enunciado científico é como um Boeing 747, que não pode nem decolar, nem pousar sem a infra-estrutura dos aeroportos. Os saberes podem ser universais, mas a água não ferve a $100^{\circ} \mathrm{C}$ senão em frágeis redes, construídas passo a passo e mobilizando um grande investimento. $\mathrm{Na}$ verdade, a ciência não se aplica, ela se replica através de investimentos enormes, e ao se replicar ela se transforma e se adapta às configurações locais.

No modelo da rede, não existem atores capazes e atores incapazes, mas apenas 
atores bem ou mal formados. A abertura à ciência é uma questão infra-estrutural que não tem nada a ver com o atavismo do espírito da cultura .

\section{Notas}

1 Martin, Henri-Jean. Le message écrit: la réception, conferência feita na Academie des Sciences Morales et Politiques, Paris, 15 de março de 1993.

2 Sobre estes três momentos da história do livro se reportar à obra de Roger Chartier, sobretudo: A ordem do livros. Brasilia: Ed. Unb, 1994; e Cavallo, Guglielmo e Chartier, Roger: História da leitura no Ocidente, 2 vol., São Paulo: Ática, 1998/1999.

3 Este mesmo movimento pode ser observado em nossa vida cotidiana em outros espaços, como os das operações bancárias, por exemplo. Com a automatização dos sistemas, o cliente hoje, realiza, ele mesmo, muitas atividades que outrora cabiam aos bancários.

4 Existe, na história da leitura, um momento sublime, descrito por Santo Agostinho em suas Confissões. Estamos em 383. Santo Agostinho visita Ambroise, o Arcebispo de Milão, em seu studiolo. Ao entrar, Agostinho tem uma visão que o deixa estupefato, a ponto de se lembrar dela treze anos mais tarde. Ele vê Ambroise ler em silêncio: "ele lia, seus olhos corriam sobre a página da qual apenas o espírito percebia o sentido, pois sua voz e sua língua estavam em repouso".

5 Sobre estes autores, se reportar a: Debray, Régis: Cours de médiologie générale, Paris: Éditions Gallimard,1991; Eisenstein, Elizabeth L.: La révolution de l'imprimé dans l'Europe des premiers temps modernes, Paris: Éditions La Découverte, 1991; Fayet-Scribe, Sylvie e Leroy, Aurette: La conquête du savoir: repérer et diffuser la connaissance: projet d'exposition, Paris: texto datilografado e ilustrado,1996; Fayet-Scribe, Sylvie: "La passion de l'orga-nisation des connaissances", entretien avec Eric de Grolier. Documentaliste, n.6, v.33, 1996; Goody, Jack: La raison graphique, la domestication de la pensée sauvage, Paris: Les Éditions de Minuit, 1986; LeroiGourhan, André: Le geste et la parole, 2 vols., Paris: Albin Michel, 1988; Lévy, Pierre: As tecnologias da inteligência. Rio de Janeiro: Editora 34, 1993.
6 de Certeau, Michel. L'invention du quotidien. Paris: 10/18, 1980.

7 Fernandez, Macedônio. Tudo e nada. Rio de Janeiro: Imago, 1998.

8 Cf. Deleuze, Gilles. Mil platôs, v.1. São Paulo: Editora 34, 1995.

9 Ver Lévy, Pierre: As tecnologias da inteligência.

10 Borges, J. L. Nueva refutación del tiempo. Obras completas. Buenos Aires: Ed. Emécé. p. 757-771.

11 Reportar-se a Latour, Bruno: Jamais fomos modernos. Rio de Janeiro: Editora 34, 1994.

12 Sobre estes dois modelos, cf. Callon, Michel. "L'évolution du rapport de l'homme à la connaissance". Texto inédito. 